\title{
The effect of tooth brushing, irrigation, and topical tetracycline administration on the reduction of oral bacteria in mechanically ventilated patients: a preliminary study
}

Saki Hayashida ${ }^{1 *}$, Madoka Funahara ${ }^{1}$, Motohiro Sekino ${ }^{2}$, Noriko Yamaguchi², Kosuke Kosai ${ }^{3}$, Souichi Yanamoto ${ }^{1}$, Katsunori Yanagihara ${ }^{3}$ and Masahiro Umeda'

\begin{abstract}
Background: One of the main causes of ventilator-associated pneumonia (VAP) is thought to be aspiration of oropharyngeal fluid containing pathogenic microorganisms. The aim of this study was to examine the effects of various oral care methods on the reduction of oral bacteria during intubation.

Methods: First, the effect of mechanical oral cleaning was investigated. The bacterial count on the tongue and in the oropharyngeal fluid was measured after tooth brushing, irrigation, and three hours after irrigation in mechanically ventilated patients at the intensive care unit (ICU).

Next, the efficacy of topical administration of tetracycline and povidone iodine on the inhibition of bacterial growth on the tongue and in the oropharyngeal fluid was examined in oral cancer patients during neck dissection.

Results: The number of bacteria in the oropharyngeal fluid was approximately $10^{5}-10^{6} \mathrm{cfu} / \mathrm{mL}$ before surgery, but increased to $10^{8} \mathrm{cfu} / \mathrm{mL}$ after intubation. Oral care with tooth brushing and mucosal cleaning did not reduce oral bacteria, while irrigation of the oral cavity and oropharynx significantly decreased it to a level of $10^{5} \mathrm{cfu} / \mathrm{mL}(p<0$. 001). However, oral bacteria increased again to almost $10^{8} \mathrm{cfu} / \mathrm{mL}$ within three hours of irrigation.

Oral bacteria did not decrease by topical povidone iodine application. In contrast, 30 min after topical administration of tetracycline, the number of oral bacteria decreased to $10^{5} \mathrm{cfu} / \mathrm{mL}$, and remained under $10^{6} \mathrm{cfu} / \mathrm{mL}$ throughout the entire experimental period of $150 \mathrm{~min}$.

Conclusions: While the present studies are only preliminary, these results indicate that irrigation of the oral cavity and oropharynx followed by topical antibiotic administration may reduce oral bacteria in mechanically ventilated patients.
\end{abstract}

Trial registration: UMIN000018318, 1 August 2015.

Keywords: Ventilator-associated pneumonia, Oral bacteria, Oral care, Irrigation, Topical antibiotic administration

\footnotetext{
* Correspondence: sakihaya@nagasaki-u.ac.jp

${ }^{1}$ Department of Clinical Oral Oncology, Nagasaki University Graduate School

of Biomedical Sciences, 41-7-1 Sakamoto, Nagasaki 852-8588, Japan

Full list of author information is available at the end of the article
} 


\section{Background}

Ventilator-associated pneumonia (VAP) is one of the major complications in the intensive care unit (ICU). It is reported that VAP occurs in 8 to $28 \%$ of mechanically ventilated patients [1-6]. Several risk factors for VAP have been identified, and some methods of prevention have been explored. The main cause of VAP is thought to be due to aspiration of oral bacteria, such as Staphylococcus aureus, Streptococcus pneumonia, or gram-negative rods [7-10]. Within $48 \mathrm{~h}$ of admission to the ICU, oral flora of critically ill patients undergoes a change to predominantly gram-negative flora that includes more virulent organisms [11-13].

$0.12 \%$ chlorhexidine is widely applied in the oral cavity to prevent VAP [14]. However, use of this agent on the mucosal surface is prohibited in Japan due to case reports of anaphylaxis. One of the main causes of VAP is thought to be due to aspiration of oropharyngeal fluid containing pathogenic microorganisms. Many investigators have attempted to reduce VAP by various oral care methods. Although some investigators have attempted to reduce VAP by tooth brushing, the results of three randomized controlled trials (RCTs) $[11,15,16]$ showed no beneficial effect of tooth brushing on the prevention of VAP. The oral care methods utilized in these studies included tooth brushing, swabbing of the palate and tongue, and suction, yet irrigation of the oral cavity and oropharynx with water was not performed. Others attempted to reduce VAP by topical administration of various agents, such as tobramycin, amphotericin B, polymyxin E, gentamycin, colistin, and vancomycin, but could not show the effects on the overall survival $[12,17,18]$.

There have been no previous studies focused on the number of oral bacteria in patients during intubation. The aims of this study were to examine the quantitative change of oropharyngeal bacteria after tooth brushing, irrigation and topical application of antiseptic or antibiotics.

\section{Methods \\ Oral care in mechanically ventilated patients Patients}

The study consisted of 45 patients (31 males, 14 females) of an average age of 65 years (range, 36-87 years) with mechanical ventilation by oral intubation who received oral care by dentists and dental hygienists at the ICU of Nagasaki University Hospital from January to September, 2014. These patients consisted of 21 elective operations and 24 emergent admissions. Causes for hospitalization in the ICU was heart disease in 22 patients, infection (septic shock) in 14 patients, cardiopulmonary arrest in 6 patients, organ transplantation in 2 patients, and perforation of the vein in a leg in one patient. Patients received dental treatment, including tooth extraction, temporary splints, and root canal treatment, except those of emergent admissions.

\section{Oral care methods}

Oral care by dental hygienist was performed the day before surgery except for patients who had had urgent hospitalization in the ICU. The methods of oral care were: removal of dental plaque with tooth brush, interdental brushing and dental flossing, tooth polishing, removal of tongue coating, and gargling.

After hospitalization in the ICU, patients underwent oral care by dentists and dental hygienists. First, the tape that secured the tracheal tube was removed, and tooth brushing, interdental brushing, and cleaning of the tongue and mucosal surface with a sponge brush or wet tissue for mouth care was performed using simultaneous suction. Next, irrigation of the oral cavity and oropharynx with $200 \mathrm{ml}$ water was performed.

\section{Evaluation}

Dental plaque, macroscopic appearance of the tongue coating, and number of oral bacteria were examined the day before surgery and the next day after surgery. Dental plaque was evaluated by the Debris Index-Simplex (DI-S) of the Oral Hygiene Index-Simplex (OHI-S) in Table 1 [19]. Quantities of plaque on the upper and lower first molars on both sides, the right upper central incisor, and the left lower central incisor were macroscopically examined. Quantity of tongue coating was classified into four categories by the method previously reported by Kojima in Table 2 [20].

The number of bacteria was measured on the dorsum of the tongue and in the oropharyngeal fluid by the Rapid Oral Bacteria Quantification System (Panasonic Healthcare Co. Ltd., Osaka, Japan) using the dielectrophoresis and impedance measurement method [21, 22]. Because the detection limit of this machine is $10^{5} \mathrm{cfu} / \mathrm{mL}$, actual bacterial counts less than this limit were displayed as $10^{5} \mathrm{cfu} / \mathrm{mL}$. Oral bacteria was measured the day before surgery and the next day after surgery. In the ICU, measurements were performed 1) before oral care, 2) after brushing and mucosal cleaning, 3) after irrigation, and 4) three hours after oral care.

\begin{tabular}{ll} 
Table $1 \mathrm{OHI}-\mathrm{S}(\mathrm{DI}-\mathrm{S})$ \\
\hline \begin{tabular}{ll} 
Score & Examination criteria \\
\hline 0 & No adhesion of plaque \\
1 & $\begin{array}{l}\text { Adhesion of plaque within } 1 / 3 \text { of dental crown or } \\
\text { regardless of the range exogenous pigmentation }\end{array}$ \\
2 & Adhesion of plaque within $1 / 3 \sim 2 / 3$ of dental crown \\
3 & Adhesion of plaque more than $2 / 3$ of dental crown
\end{tabular} \\
\hline
\end{tabular}

Calculation method: Total score of tested 6 teeth $\div 6$

Case of loss of tested tooth: Case of loss of the first molar, substitute by the second molar 
Table 2 Classification of degree of adhesion of tongue coat adhesion by method of Kojima

\begin{tabular}{ll}
\hline First-degree & $\begin{array}{l}1 / 3 \text { dorsum of the tongue and thin } \\
\text { Second-degree }\end{array}$ \\
$\begin{array}{l}2 / 3 \text { dorsum of the tongue and thin or } 1 / 3 \\
\text { dorsum of the tongue and thick } \\
\text { Third-degree }\end{array}$ & $\begin{array}{l}2 / 3 \text { or more dorsum of the tongue and thin or } \\
2 / 3 \text { dorsum of the tongue and thick }\end{array}$ \\
Fourth-degree & $2 / 3$ or more dorsum of the tongue and thick
\end{tabular}

\section{Statistical analysis}

The differences in DI-S and Tongue Coating Indexes before and after intubation, and in number of bacteria before and after oral care the day before surgery were analyzed statistically using Mann-Whitney's $U$ Test. Further, in the ICU, those before oral care, after brushing and mucosal cleaning, after irrigation, and three hours later were also analyzed by Kruskal-Wallis test.

\section{Topical administration of povidone iodine or tetracycline Patients}

Fifteen patients with oral cancer who underwent neck dissection under general anesthesia were enrolled in the study. After intubation, the oral cavity and oropharynx were irrigated sufficiently with $500 \mathrm{ml}$ of saline. In all patients, $1500 \mathrm{mg}$ of ampicillin/sulbactam was administered parenterally at the start of surgery. The patients were divided into three groups: 1 ) control group (5 patients), 2) povidone iodine group (5 patients), and 3) tetracycline group (5 patients).

\section{Treatment and evaluation}

In the povidone iodine group, $5 \mathrm{ml}$ of $10 \%$ povidone iodine solution was applied in the oral cavity after irrigation. The tetracycline group received topical administration of $10 \mathrm{~g}$ of $3 \%$ tetracycline ointment on the dorsum of the tongue. The number of bacteria on the dorsum of the tongue and in the oropharyngeal fluid was measured every $15 \mathrm{~min}$ by the same method of the first examination until neck dissection was finished. Additionally, the concentration of tetracycline in the oropharyngeal fluid was measured at five minutes, one and two hours after topical administration by bioassay. Statistical analysis was not done because of a small number of patients.

\section{Results}

\section{Oral care in mechanically ventilated patients}

The average DI-S index before surgery and after intubation was 0.33 and 0.47 , respectively. There was no increase of DI-S index the next day after intubation, due possibly to adequate perioperative oral management in our hospital. In contrast, the tongue coating index increased the next day after intubation. A thin coat was present in most cases, but this was easily removed by swab (Fig. 1).

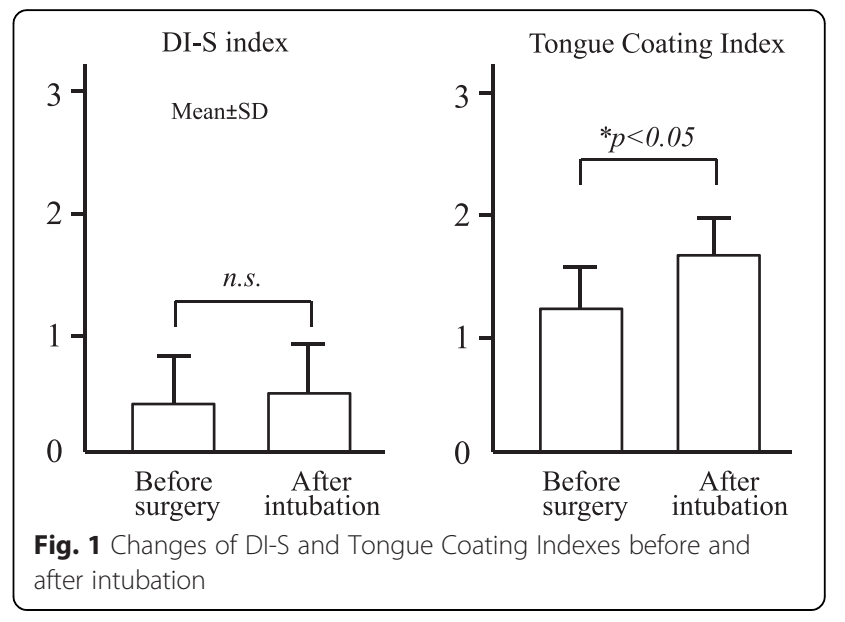

The number of bacteria in the oropharyngeal fluid before surgery was approximately $10^{5}-10^{6} \mathrm{cfu} / \mathrm{mL}$. After hospitalization in the ICU, the bacteria in the oropharyngeal fluid significantly increased compared to before intubation $(p<0.001)$, to approximately $10^{8} \mathrm{cfu} / \mathrm{mL}$. Oral care with tooth brushing and mucosal cleaning didn't reduce the number of oral bacteria. But irrigation of the oral cavity and oropharynx significantly decreased oral bacteria to a level of $10^{5} \mathrm{cfu} / \mathrm{mL}(p<0.001)$. However, three hours after irrigation, oral bacteria significantly increased to almost $10^{8} \mathrm{cfu} / \mathrm{mL}$ again $(p<0.001)$ (Fig. 2). The number of bacteria on the dorsum of the tongue showed a result different from the oropharyngeal fluid. Oral care with tooth brushing and mucosal cleaning significantly reduced the number of oral bacteria $(p<0.001)$. Furthermore, irrigation of oral cavity significantly decreased oral bacteria $(p<0.001)$. However, three hours after irrigation, the number of bacteria on the dorsum of the tongue again increased (Fig. 3).

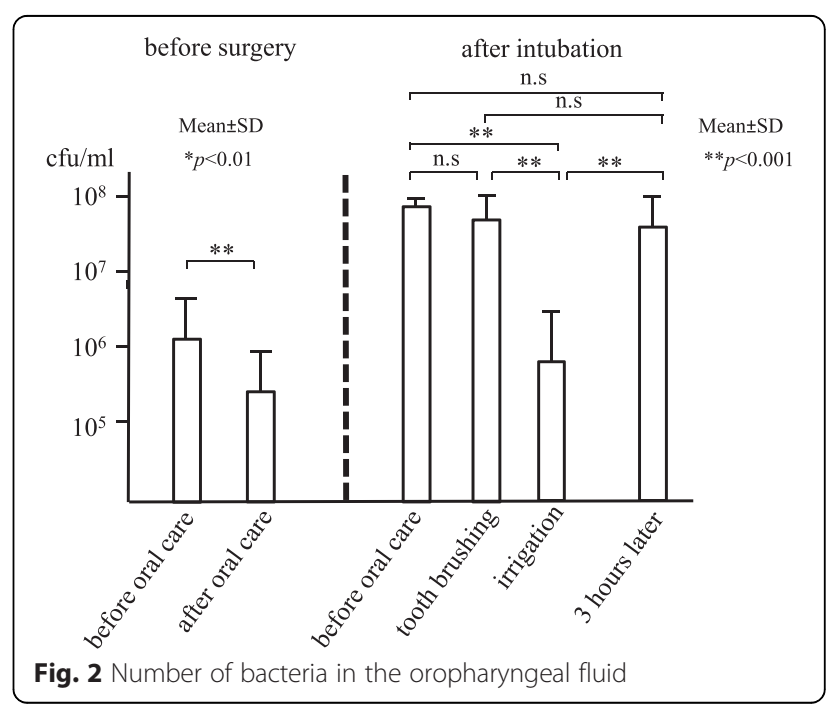




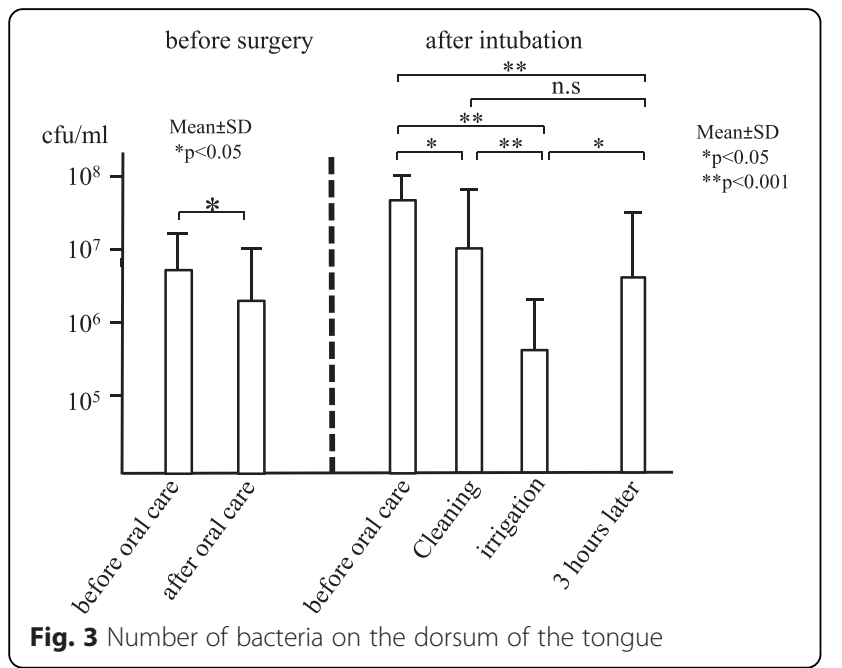

Topical administration of povidone iodine or tetracycline In patients receiving topical administration of povidone iodine, the number of bacteria on the dorsum of the tongue and in the oropharyngeal fluid was slightly decreased compared to the control group. In contrast, topical administration of tetracycline ointment showed remarkable effects on the reduction of bacteria. Thirty minutes after topical administration, the number of bacteria on the dorsum of the tongue and in the oropharyngeal fluid decreased to $10^{5} \mathrm{cfu} / \mathrm{mL}$, and remained under $10^{6} \mathrm{cfu} / \mathrm{mL}$ throughout the entire experimental period (Fig. 4).

The concentration of tetracycline in the oropharyngeal fluid after topical administration on the dorsum of the tongue was $1.70 \mu \mathrm{g} / \mathrm{mL}$ at five minutes, $89.3 \mu \mathrm{g} / \mathrm{mL}$ at one hour, and $183.4 \mu \mathrm{g} / \mathrm{mL}$ at two hours (Fig. 5).

\section{Discussion}

VAP is an airway infection developing more than $48 \mathrm{~h}$ after intubation, which is the leading cause of death among hospital-acquired infections. The Institute for
Healthcare Improvement (IHI) proposed four prophylaxis for prevention of VAP (VAP bundle) consisting of head-ofbed elevation, a daily "sedation vacation" and a readinessto-wean assessment, peptic ulcer disease prophylaxis, and deep vein thrombosis prophylaxis. Additionally, a fifth prophylaxis, oral decontamination with chlorhexidine, was added in 2010 [23]. However, oral hygiene practices of tooth brushing, removal of tongue coating, swabbing of oral mucosa, and irrigation were not included in the VAP bundle.

One of the main causes of VAP is thought to be due to aspiration of oropharyngeal fluid containing pathogenic microorganisms. Many investigators have attempted to reduce VAP by various oral care methods. Mori et al. [24] reported that 1252 mechanically ventilated patients who received oral care consisting of swabbing with povidone iodine gargle, tooth brushing, and irrigation with $300 \mathrm{ml}$ of acidic water showed a significantly lower frequency of VAP compared to the 414 patients who did not receive oral care. Sona et al. [25] also described that the implementation of a simple, low-cost oral care protocol of tooth brushing, rinsing with tap water, and subsequent application of a $0.12 \%$ chlorhexidine gluconate chemical solution led to a significantly decreased risk of acquiring VAP. However, their studies were performed with historically controlled patients and therefore the evidence levels were not high. Munro et al. [11], Pobo et al. [15], and Lorente et al. [16] conducted randomized controlled studies of the effect of tooth brushing on the prevention of VAP and concluded that mechanical tooth brushing did not show any significant efficacy. Some investigators attempted topical antibiotic application for the prevention of VAP, but they were unable to find any effect on the improvement of outcome of mechanically ventilated patients $[12,17,18]$. Hillier et al. stated in a literature review that no consensus has been established yet on best practices for oral hygiene in mechanically

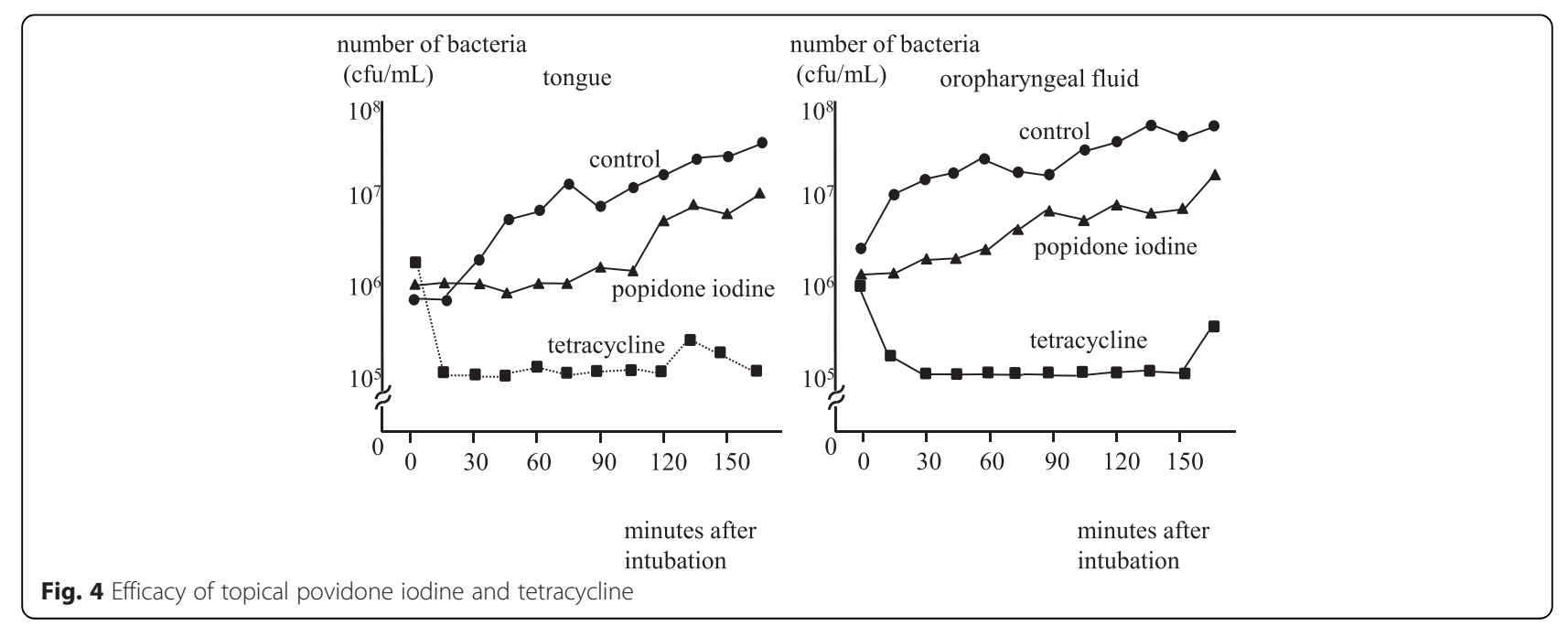




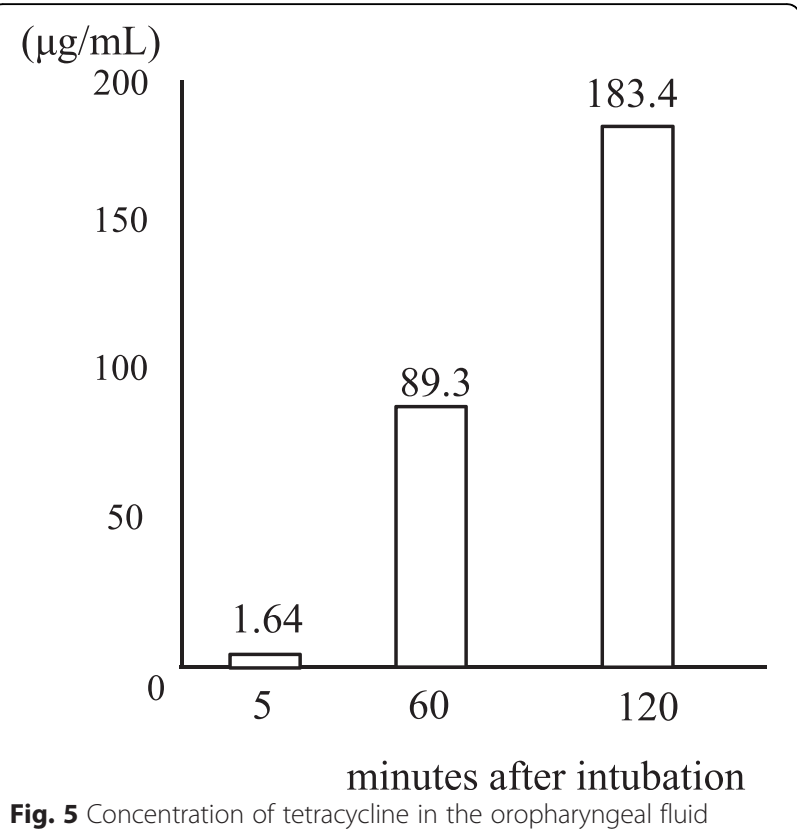

ventilated patients, although chlorhexidine was the most popular oral care method [14].

The three RCTs of Munro [11], Pobo [15], and Lorente [16] concluded that mechanical oral care was not effective for preventing VAP, as mentioned above. The current preliminary study also demonstrates that tooth brushing and mucosal cleaning with suction had little effect on reducing the number of bacteria in the oropharyngeal fluid. However, tongue and oropharyngeal bacteria decreased significantly after irrigation with $200 \mathrm{ml}$ tap water in the oral cavity and oropharynx. In their RCTs, $0.12 \%$ chlorhexidine was applied in the oral cavity every eight hours. We used $10 \%$ povidone iodine solution and examined its effect on reducing bacteria on the tongue and in the oropharyngeal fluid, because use of $0.12 \%$ chlorhexidine on mucosal surfaces is prohibited in Japan due to a case report of anaphylaxis. As a result, the increase of oral bacteria was slightly inhibited after topical application of $10 \%$ povidone iodine solution.

The number of bacteria on the tongue and in the oropharyngeal fluid significantly decreased to the level of before surgery when irrigation was added after tooth brushing. These findings indicate that irrigation is essential to reduce oral bacteria in mechanically ventilated patients. However, oral bacteria increased again only $3 \mathrm{~h}$ after irrigation. We think that the procedures described in the above RCTs were not sufficient to decrease oral bacteria due to the lack of irrigation of the oral cavity and prolonged oral care interval. It has been suggested that mechanical oral care requires irrigation and frequent practice: at least every $3 \mathrm{~h}$.
This study demonstrated that topical administration of tetracycline ointment, an approach different from frequent practice, is an alternative method to reduce oral bacteria. After application of tetracycline ointment on the dorsum of tongue, bacteria both on the tongue and oropharyngeal fluid rapidly decreased to $10^{5} \mathrm{cfu} / \mathrm{mL}$ or less, and the effects lasted for at least $150 \mathrm{~min}$. We could not clarify how long the effect lasted, because the surgery finished within $150 \mathrm{~min}$. In contrast, topical administration of povidone iodine showed limited effects on reducing oral bacteria.

Some investigators have reported the effects of oral decontamination on the prevention of pneumonia in ventilated patients. Rodriguez-Roldán et al. [17], applied paste containing tobramycin, amphotericin $\mathrm{B}$, and polymyxin E topically in the oral cavity in 13 ventilated patients, and concluded that nosocomial pneumonia could be prevented by local application of nonabsorbable antibiotics to the oropharynx, although the overall mortality was not improved. Abele-Horn et al. [12] reported that 58 patients receiving topical administration of the same paste demonstrated a decreased incidence of pneumonia compared to the 30 control patients; however, the length of the ICU stay and mortality were similar between the groups. Bergmans et al. [18] also reported that the 92 patients who received topical antimicrobial prophylaxis consisting of an Orabase with gentamycin, colistin, and vancomycin had a reduced frequency of developing pneumonia compared to the 153 patients who did not undergo such a procedure, although this was not associated with shorter duration of ventilation or better survival. Because these authors' studies failed to demonstrate the efficacy of topical antibiotic administration on the mortality of mechanically ventilated patients, this method has not become a standard treatment.

The present results, demonstrated by bacterial count, showed that tooth brushing and mucosal swab were able to reduce bacteria little in the oropharyngeal fluid, but was significantly decreased after irrigation, and that topical administration of tetracycline ointment on the dorsum of the tongue strongly inhibited the growth of bacteria. The reservoir of microorganisms in the oropharyngeal fluid is not clear. We examined the change of the number of bacteria on the buccal mucosa, palate, dorsum of the tongue, and in the oropharyngeal fluid after intubation, and clarified that bacteria increased rapidly on the tongue and in the oropharyngeal fluid, while that on the buccal mucosa and palate did not during intubation [26]. Some investigators have stated that dental plaque is a reservoir of oropharyngeal bacteria and that removal of dental plaque is important for the prevention of pneumonia in ventilated patients $[27,28]$. On the other hand, Penel et al. [29] reported that edentulous patients, who are completely plaque-free, develop surgical site infection (SSI) as 
frequently as those with teeth in head and neck cancers, which indicated that dental plaque was not a main reservoir of oropharyngeal bacteria. We believe that the surface of the dorsum of the tongue may be one of the reservoirs of intraoral bacteria, and that it is necessary to inhibit bacteria growth on the tongue for prevention of VAP. Our report is unique in that it has demonstrated topical administration of tetracycline on the tongue is able to reduce bacteria in the oropharyngeal fluid, as well as on the tongue. However, before clinical application, we think it is necessary to examine the prevalence of species including resistant bacteria after topical administration of tetracycline, especially in case of prolonged intubation.

\section{Conclusions}

Oral care with irrigation of the oral cavity and oropharynx followed by topical antibiotic administration may reduce oral bacteria in mechanically ventilated patients.

\section{Abbreviations}

DI-S, debris index-simplex; IHI, Institute for Healthcare Improvement; OHI-S, oral hygiene index-simplex; RCTs, randomized controlled trials; SSI, surgical site infection; VAP, ventilator-associated pneumonia; ICU, intensive care unit

\section{Acknowledgements}

Not applicable.

\section{Funding}

Not applicable.

\section{Availability of data and materials}

We state that the clinical data and personal details will not be made available in order to protect the participants identity.

\section{Authors' contributions}

HS designed the study, collected data, drafted and wrote the manuscript. FM participated in the design of the study, help in the collecting of data. SM participated in the design of the study, the data and the manuscript. YN participated in the design of the study and help in collecting of data. KK participated in the design of the study, collected data. YS participated in the design of the study, performed statistical analyses. YK participated in the design of the study, collected data. UM designed the study, supervised interpretation of the data and the drafting of the manuscript. All authors read and approved the final manuscript.

\section{Competing interests}

The authors declare that they have no competing interests.

\section{Consent for publication}

Not applicable.

\section{Ethics approval and consent to participate}

Ethics approval of Institutional Review Board of Nagasaki University Hospital was obtained and the committee's reference number was No.13062419. We obtained informed consent verbally from all participants. If it could not be informed consent in the patient himself in the emergency surgery, we got the consent verbally to their family.

\section{Author details}

${ }^{1}$ Department of Clinical Oral Oncology, Nagasaki University Graduate Schoo of Biomedical Sciences, 41-7-1 Sakamoto, Nagasaki 852-8588, Japan. ${ }^{2}$ Division of intensive care, Nagasaki University Hospital, 41-7-1 Sakamoto, Nagasaki 852-8588, Japan. ${ }^{3}$ Department of Laboratory Medicine, Nagasaki University Graduate School of Medicine, 41-7-1 Sakamoto, Nagasaki 852-8588, Japan.
Received: 8 July 2015 Accepted: 26 May 2016

Published online: 07 June 2016

\section{References}

1. Chastre J, Fagon JY. Ventilator-associated pneumonia. Am J Respir Crit Care Med. 2002;165:867-903.

2. Haley RW, Hooton TM, Culver DH, Stanley RC, Emori TG, Hardison CD, Quade D, Shachtman RH, Schaberg DR, Shah BV, Schatz GD. Nosocomial infections in US hospitals, 1975-1976: estimated frequency by selected characteristics of patients. Am J Med. 1981;70:947-59.

3. Pennington JE. Nosocomial respiratory infection. In: Mandell GL, Douglas Jr RG Bennet JE, editors. Principles and Practice of Infectious Disease. St. Louis: Churchill Livingstone; 1990. p. 2199-205.

4. Chastre J, Fagon JY. Pneumonia in the ventilator-dependent patient. In: Tobin MJ, editor. Principles and Practice of Mechanical Ventilation. New York: McGraw-Hill; 1994. p. 857-90.

5. Centers for Disease Control and Prevention. Monitoring hospital-acquired infections to promote patient safety: United States, 1990-1999. MMWR. 2000:49:149-53.

6. National Nosocomial Infections Surveillance (NNIS) System. National Nosocomial Infections Surveillance (NNIS) System report, data summary from January 1990-May 1999, issued June 1999. Am J Infect Control. 1999; 27:520-32.

7. Craven DE, Driks MR. Nosocomial pneumonia in the intubated patient Semin Respir Infect. 1987;2:20-33.

8. Torres A el-Ebiary M, González J, Ferrer M, Puig de la Bellacasa, Gené A, Martos A, Rodriguez-Roisin R. Gastric and pharyngeal flora in nosocomial pneumonia acquired during mechanical ventilation. Am Rev Respir Dis. 1993:148:352-7.

9. Greene R, Thompson S, Jantsch HS, Teplick R, Cullen DJ, Greene EM, Whitman GJ, Hulka CA, Llewellyn HJ. Detection of pooled secretions above endotracheal-tube cuffs: value of plain radiographs in sheep cadavers and patients. AJR Am J Roentgenol. 1994:163:1333-7.

10. Valles J, Artigas A, Rello J, Bonsoms N, Fontanals D, Blanch L, Fernández R, Baigorri F, Mestre J. Continuous aspiration of subglottic secretions in preventing ventilator-associated pneumonia. Ann Intern Med. 1995;122:179-86.

11. Munro CL, Grap MJ, Jones DJ, McClish DK, Sessler CN. Chlorhexidine, toothbrushing, and preventing ventilator-associated pneumonia in critically III adults. Am J Crit Care. 2009:18:428-37.

12. Abele HM, Dauber A, Bauernfeind A, Russwurm W, Seyfarth MI, Gleich P, Ruckdeschel G. Decrease in nosocomial pneumonia in ventilated patients by selective oropharyngeal decontamination (SOD). Intensive Care Med. 1997;23:187-95.

13. Johanson Jr WG, Seidenfeld JJ, de los Santos R, Coalson JJ, Gomez P. Prevention of nosocomial pneumonia using topical and parenteral antimicrobial agents. Am Rev Respir Dis. 1988;137:265-72.

14. Hillier B, Wilson C, Chamberlain D, King L. Preventing ventilator-associated pneumonia through oral care, product selection, and application method. AACN Advanced Critical Care. 2013;24:38-58.

15. Pobo A, Lisboa T, Rodriguez A, Sole R, Magret M, Trefler S, Gómez F, Rello J. A randomized trial of dental brushing for preventing ventilator-associated pneumonia. Chest. 2009:136:433-9.

16. Lorente L, Lecuona M, Jiménez A, Palmero S, Pastor E, Lafuente N, Ramos MJ Mora ML, Sierra A. Ventilator-associated pneumonia with or without toothbrushing: a randomized controlled trial. Eur J Clin Microbiol Infect Dis. 2012;31:2621-9.

17. Rodríguez-Roldán JM, Altuna-Cuesta A, López A, Carrillo A, Garcia J, León J, Martínez-Pellús AJ. Prevention of nosocomial lung infection in ventilated patients: use of an antimicrobial pharyngeal nonabsorbable paste. Crit Care Med. 1990;18: 1239-42.

18. Bergmans DCJJ, Bonten MJM, Gaillard CA, Paling JC, Geest S, Tiel FH, Beysens AJ, Leeuw PW, Stobberingh EE. Prevention of ventilator-associated pneumonia by oral decontamination: a prospective, randomized, doubleblind, placebo-controlled study. Am J Respir Crit Care Med. 2001;164:382-8.

19. Malmö University. Simplified Oral Hygiene Index; OHI-S. Greene and Vermillion. 1964 Utskrift fran Malmo hogskolas webbplats. http://www.mah.se/CAPP/ Methods-and-Indices/Oral-Hygiene-Indices/Simplified-Oral-Hygiene-Index-OHI-S/ Accessed July 2, 2016.

20. Kojima K. Clinical studies on the coated tongue. Jpn J Oral Maxillofac Surg 1985;31:1659-78. 
21. Suehiro J, Yatsunami R, Hamada R, Hara M. Quantitative estimation of biological cell concentration suspended in aqueous medium by using dielectrophoretic impedance measurement method. J Phys D Appl Phys J Phys D Appl Phya. 1999:32:2814-20.

22. Hirota K, Inagaki S, Hamada R, Ishihara K, Miyake Y. Evaluation of a rapid oral bacteria quantification system using dielectrophoresis and the impedance measurement. Biocontrol Science. 2014;19:45-9.

23. Institute for Healthcare Improvement. Implement the ventilator bundle. Institute for Healthcare Improvement Web site. http://www.ihi.org//HI/Topics/ CriticalCare/IntensiveCare/Changes/ImplementtheVentilatorBundle. htm Accessed July 2, 2016.

24. Mori H, Hirasawa H, Oda S, Shiga H, Matsuda K, Nakamura M. Oral care reduces incidence of ventilator-associated pneumonia in ICU populations. Intensive Care Med. 2006;32:230-6.

25. Sona CS, Zack JE, Schallom ME, McSweeney M, McMullen K, Thomas J, Coopersmith CM, Boyle WA, Buchman TG, Mazuski JE, Schuerer DJE. The impact of a simple, Low-cost oral care protocol on ventilator-associated pneumonia rates in a surgical intensive care unit. J Intensive Care Med. 2009;24:54-62.

26. Funahara M, Hayashida S, Sakamoto Y, Yanamoto S, Kosai K, Yanagihara K, Umeda M. Efficacy of topical antibiotic administration on the inhibition of perioperative oral bacterial growth in oral cancer patients: a preliminary study. Int J Oral Maxillofac Surg. 2015;44:1225-30.

27. Scannapieco FA, Stewart EM, Mylotte JM. Colonizaition of dental plaque by respiratory pathogens in medical intensive care patients. Crit Care Med. 1992;20:740-5.

28. Fourrier F, Duvivier B, Boutigny H, Roussel-Delvallez M, Chopin C. Colonization of dental plaque: a source of nosocomial infections in intensive care unit patients. Crit Care Med. 1998;26:301-8.

29. Penel N, Fournier C, Lefebvre D, Lefebvre JL. Multivariate analysis of risk factors for wound infection in head and neck squamous cell carcinoma surgery with opening of mucosa. Study of 260 surgical procedures. Oral Oncol. 2005:41:35-44.

\section{Submit your next manuscript to BioMed Central and we will help you at every step:}

- We accept pre-submission inquiries

- Our selector tool helps you to find the most relevant journal

- We provide round the clock customer support

- Convenient online submission

- Thorough peer review

- Inclusion in PubMed and all major indexing services

- Maximum visibility for your research

Submit your manuscript at www.biomedcentral.com/submit

C Biomed Central 